\title{
UV inhibition of the nematode infection process in Arthrobotrys oligospora and Dactylaria candida
}

\author{
E. FrIMAN*
}

Department of Microbial Ecology, University of Lund, Ecology Building, Helgonavägen 5, S-223 62 Lund, Sweden

(Received 15 January 1993; revised 20 May 1993; accepted 1 June 1993)

\begin{abstract}
The effects of UV irradiation on infection of nematodes by two nematode-trapping fungi were studied. Five minutes UV irradiation of the fungi caused an inhibition of the infection process in both Arthrobotrys oligospora and Dactylaria candida. After the nematodes were captured, the infection process stopped; the nematodes were still moving at a time when the nematodes in untreated controls were completely digested. The UV-irradiated fungi were still alive and were capable of further growth. After $15 \mathrm{~min}$ UV irradiation the number of captured nematodes was also reduced. Inhibition studies with cycloheximide showed differences between the two fungi. The nematodes were still alive $24 \mathrm{~h}$ after capture by treated cultures of $A$. oligospora while the infection process was normally completed by $D$. candida. There were minor differences in the peptide pattern on a SDS-PAGE gel between proteins from untreated and UV-irradiated mycelia of both fungi. Both the results from inhibition experiments and changes in the peptide pattern after UV irradiation suggest that the target molecules affected by UV irradiation may have been proteins involved in the infection process, and not the DNA. No effect of UV irradiation was observed on molecules that had been suggested previously to be involved in the nematode infection process (toxins, lectins and proteases).
\end{abstract}

\section{Introduction}

Arthrobotrys oligospora and Dactylaria candida capture nematodes with the aid of adhesive networks and adhesive knobs, respectively. When a nematode comes into contact with a trap a sequence of events starts which is basically the same in both fungi (Dowsett \& Reid, $1977 a, b$; Veenhuis et al., 1985, 1989; Wimble \& Young, 1984; Nordbring-Hertz et al., 1993). The nematode becomes firmly attached to the trap. The fungus then penetrates the nematode cuticle with a small hyphal peg which grows out from the trap. Inside the nematode an infection bulb is formed from which hyphae grow out. Within a few hours of attachment the nematode stops moving and appears dead. Later on the nematode will be filled with hyphae and completely digested by the fungus. The molecular details of the infection process, starting with the adhesion of a nematode to the trap and ending when the nematode is completely digested and new traps are formed, are not known, although a toxin (Shepherd, 1955; Olthof \& Estey, 1963), a lectin (Nordbring-Hertz \& Mattiasson, 1979) and a serine-protease (Tunlid \& Janson, 1991), may be involved.

During previous experiments designed to inhibit

*Tel. $+4646108615 ;$ fax +4646104158 . capture of nematodes by $A$. oligospora by using chemical or physical agents it was observed that short-term UV irradiation strongly reduced the immobilization of the captured nematodes without affecting adhesion. In the present work this effect has been studied in more detail. UV irradiation can destroy not only DNA but also other molecules that absorb the irradiation. If the target of UV irradiation in these experiments was DNA, new proteins must be induced during the nematode infection process and similar results would be obtained if protein synthesis was inhibited. Therefore the results were compared with effects of the protein synthesis inhibitor cycloheximide and the transcription inhibitor actinomycin $D$. The effects of UV irradiation on activities of molecules proposed to be involved in the nematode infection process (toxin, lectin and proteases) and on the polypeptide pattern of fungal cell extracts were also investigated.

\section{Methods}

Fungi and culture conditions. Arthrobotrys oligospora (ATCC 24927) and Dactylaria candida (CBS 220.54) were grown on a modified, lownutrient medium, supplemented with L-phenylalanyl-L-valine to stimulate trap formation (Nordbring-Hertz, 1973). The medium had the following composition: $\mathrm{KCl} 1.0 \mathrm{~g} \mathrm{l}^{-1}, \mathrm{MgSO}_{4} 0.2 \mathrm{~g} \mathrm{l}^{-1}, \mathrm{ZnSO}_{4} \cdot 7 \mathrm{H}_{2} \mathrm{O}$ $0.88 \mathrm{mg} \mathrm{l}^{-1}, \mathrm{FeCl}_{3} .6 \mathrm{H}_{2} \mathrm{O} 3.0 \mathrm{mg} \mathrm{l}^{-1}$, thiamin. $\mathrm{HCl} 0.2 \mathrm{mg} \mathrm{l}^{-1}$, biotin 
$0.005 \mathrm{mg} \mathrm{l}^{-1}$, L-phenylalanyl-L-valine $0.1 \mathrm{~g}^{-1}, \mathrm{pH}$ adjusted to 6.5 with $\mathrm{NaOH}$, agar $10.0 \mathrm{~g} \mathrm{l}^{-1}$. When experiments were performed with $A$. oligospora, a few drops of a water suspension containing 20-100 nematodes were added 2-3 d after inoculation in order to enhance trap formation. All experiments were performed with colonies rich in traps. In capture experiments with $A$. oligospora the ratio of traps to nematodes was at least $4: 1$ since a lower ratio often resulted in reduced capture even in controls. In experiments with inhibitors the fungi were grown on pieces of dialysis membrane placed on the agar surface (Nordbring-Hertz, 1983). For toxicity tests, SDS-PAGE, lectin and protease assays the fungi were grown using a method that allows an abundant trap formation in liquid culture (Friman et al., 1985). The culture vessels consisted of modified cylindrical separating funnels filled with $500 \mathrm{ml}$ growth medium. Aeration and agitation were achieved by heavy air bubbling from the bottom of the vessel with the aid of a membrane pump. The air was sterilized by passage through a $0.22 \mu \mathrm{m}$ Millipore filter before entering the vessel by means of an injection needle fitted into a silicone rubber membrane. The growth medium was $0.01 \%$ soya peptone (neutralized, Oxoid) supplemented with $0.005 \%$ L-phenylalanine and $0.005 \% \mathrm{~L}$-valine to stimulate trap formation. Liquid cultures of $A$. oligospora were inoculated with conidia and cultivated for $5 \mathrm{~d}$. Because of the lack of conidial production, $D$. candida cultures were inoculated with pieces from agar cultures or with a few millilitres from an old liquid culture and were grown for $10 \mathrm{~d}$ to compensate for the lower growth rate. Liquid cultures were harvested by filtering through a $10 \mu \mathrm{m}$ nylon mesh and washed with distilled water.

Nematodes. The free-living nematode Panagrellus redivivus (Goodey) was grown axenically at $20^{\circ} \mathrm{C}$ in $50 \mathrm{ml}$ Erlenmeyer flasks, each containing $4.3 \mathrm{ml} 4 \%$ (w/v) Soya-peptone (Oxoid) and $100 \mathrm{mg}$ Bactoliver (Difco), and was subcultured every 10-11 d. Nematodes from cultures $6-10 \mathrm{~d}$ old were transferred to sterile test tubes and 5-10 $\mathrm{ml}$ sterile water was added. The liver extract settled at the bottom of the tube and the nematodes in a layer on top of the liver extract. The nematodes were transferred to a new tube and this washing procedure was repeated six times. If the nematode suspension was not used immediately it was kept in the refrigerator for a few days.

UV irradiation. UV irradiation was performed with a fluorescent tube (Philips TUV 15W). The measured intensity of the UV irradiation on the agar fungal cultures at a distance of $51 \mathrm{~cm}$ from the UV source was $9.5 \mu \mathrm{W} \mathrm{cm}$ in the interval $250-260 \mathrm{~nm}\left(24 \mu \mathrm{W} \mathrm{cm}{ }^{2}\right.$ in the interval $250-360 \mathrm{~nm}$ ). The UV irradiation was performed at room temperature and did not influence the sample temperature. After irradiation, pieces of agar (about $1 \times 1 \mathrm{~cm}^{2}$ ) from outgrown cultures with well-developed traps were cut out and placed in empty Petri dishes. One drop of a nematode suspension was added on top of the agar block. The following day, free nematodes, captured but still moving nematodes, and captured non-moving nematodes were counted. The ratios of free nematodes to total nematodes and moving nematodes to captured nematodes were calculated. Mean values and standard deviations of 10-15 replicates (together 100-350 nematodes per treatment) were calculated after arcsin $\sqrt{ } x$ transformation ( $x$ being the ratio of free nematodes to total nematodes or moving nematodes to captured nematodes) (Sokal \& Rohlf, 1981). Since the standard deviations after back-transformation are not symmetrically distributed about the mean the standard deviations are expressed as ranges.

The mycelia from liquid cultures intended for SDS-PAGE were spread on a plastic lid in as small a volume of distilled water as possible to keep it moist and fluid. The lid was placed on a rotary shaker at 150 r.p.m. Since the UV lamp was at a distance of only $33 \mathrm{~cm}$ in this experiment the intensity of the UV light on the samples surface was increased. However, the mycelium was suspended in water instead of growing on a flat agar surface and this may have reduced the exposure to UV radiation. The biological effects of UV irradiation on mycelia from liquid cultures were therefore investigated by spreading a few drops of the irradiated mycelia on an agar surface, adding nematodes and counting the nematodes the next day as outlined above.

Mycelial extracts intended for measurements of proteolytic and haemagglutinating activity were UV-irradiated in plastic well plates with a flat bottom and well diameters of $35 \mathrm{~mm}$. The volume of mycelial extract in each well was $1 \mathrm{ml}$. The conditions during UV irradiation were the same as for liquid culture mycelia.

Viability test. Vital staining of the fungi was performed with methylene blue (Gurr, 1960). Blue-stained hyphae were regarded as non-viable. For tests of growth ability, dialysis membranes with $A$. oligospora and $D$. candida UV irradiated for $0,3,5$ or 15 min were placed on cornmeal agar diluted 1:10.

Inhibition with cycloheximide and actinomycin $D$. The effect of cycloheximide (Sigma) was tested at 1,25 or $100 \mu \mathrm{g} \mathrm{ml}^{-1}$ and actinomycin D (Sigma) at 20 or $100 \mu \mathrm{g} \mathrm{ml}^{-1}$. Dialysis membranes with outgrown mycelium bearing traps were transferred from the agar surface to empty Petri dishes and flooded with the different test solutions. After $1 \mathrm{~h}$ the test solution was replaced with a suspension of nematodes in the same solution. One hour after addition of nematodes the solutions were removed from control dialysis membranes and the membranes were washed carefully with distilled water. Then new nematodes, suspended in distilled water, were added to the washed dialysis membranes. Free, captured but moving, and captured nonmoving nematodes were counted the next day. Mean values and standard deviations were calculated as above. Numbers of replicates for each treatment (1-6) and total numbers of counted captured nematodes (33-1300) are indicated in Table 1. The effect of the inhibitors on fungal growth was tested by inoculating the fungi onto diluted $(1: 10)$ cornmeal agar containing $0,1,25$ or $100 \mu \mathrm{g}$ cycloheximide $\mathrm{ml}^{-1}$ and water agar containing 0,20 or $100 \mu \mathrm{g}$ actinomycin $\mathrm{D} \mathrm{ml}^{-1}$.

Mycelial extracts for SDS-PAGE and measurements of proteolytic and haemagglutinating activity. The mycelium was transferred to a mortar and ground under liquid nitrogen. After grinding, the powder obtained was further homogenized on ice in a close-fitting Dounce glass-glass homogenizer (100 strokes). The second step was performed in both the presence and absence of potassium phosphate buffer, $\mathrm{pH} 7 \cdot 0$. The homogenate was centrifuged at $10000 \mathrm{~g}$ for $15 \mathrm{~min}$. To protect the proteins during storage, DMSO was added to the supernatant at a final concentration of $5 \%(\mathrm{v} / \mathrm{v})$. The mycelial extract so obtained was stored frozen.

$S D S-P A G E$. Samples of the prepared mycelia were diluted $1: 1$ or more in a sample buffer containing $0.05 \mathrm{M}$-Tris $/ \mathrm{HCl}(\mathrm{pH} 6.8), 5 \%$ $(\mathrm{w} / \mathrm{v})$ dithiothreitol, $2 \%(\mathrm{w} / \mathrm{v}) \mathrm{SDS}, 12 \%(\mathrm{v} / \mathrm{v})$ glycerol and $0.01 \%$ $(\mathrm{w} / \mathrm{v})$ bromophenol blue and boiled for $5 \mathrm{~min}$. The electrophoresis was performed on ExcelGels (precast gradient gels from Pharmacia). The gels were stained with Coomassie R250.

Proteolytic activity. Proteolytic activity was measured by the method of Chavira et al. (1984). The analysis was performed at pH 5.9 since mycelial extracts from liquid cultures of $A$. oligospora had an acid $\mathrm{pH}$ optimum (Persson \& Friman, 1993). A suspension of the insoluble protein-dye conjugate Azocoll $\left(5 \mathrm{mg} \mathrm{ml}^{-1}\right)$ was washed in $0.05 \mathrm{M}$ potassium phosphate buffer, $\mathrm{pH} 5 \cdot 9$, for $2 \mathrm{~h}$. Immediately before use the buffer was filtered and the Azocoll resuspended in fresh buffer. Because of the insolubility of the Azocoll, the suspension was stirred vigorously during the transfer of the suspension to test tubes. One millilitre of the Azocoll suspension was mixed with $100 \mu \mathrm{l}$ of the sample and incubated overnight at room temperature with agitation ( 300 r.p.m.). The reaction was stopped by removing the Azocoll by filtering each sample through a Pasteur pipette plugged with cotton wool. The absorbance was measured at $520 \mathrm{~nm}$. One proteolytic unit (PU) was defined as $\Delta A_{520} \mathrm{ml}^{-1} \mathrm{~h}^{-1}$. 
Haemagglutinating assay. Haemagglutinating activity was measured in microtitre v-plates. Trypsinized and glutaraldehyde-treated human blood group A erythrocytes (Sigma) were diluted to a $2 \%(\mathrm{v} / \mathrm{v})$ suspension with $20 \mathrm{~mm}$-sodium phosphate buffer, $\mathrm{pH} 7 \cdot 4$, containing $0.15 \mathrm{M}-\mathrm{NaCl}$ (PBS). The protein solution was diluted in a twofold series with PBS. Twenty microlitres was added to each well, together with an equal volume of the erythrocyte suspension. The mixture was kept at room temperature for $1 \mathrm{~h}$ and examined for haemagglutination (Rosén et al., 1992). The haemagglutinating activity was expressed as the number of wells showing haemagglutination.

Identification of the A. oligospora lectin by SDS-PAGE. Equal volumes of mycelial extracts and either mucin-Sepharose (to bind the A. oligospora lectin: Rosén et al., 1992) or PBS (control) were mixed and stored at $4{ }^{\circ} \mathrm{C}$ with gentle agitation for $20 \mathrm{~h}$. Haemagglutinating activity and the polypeptide pattern on SDS-PAGE gels were compared between mucin-treated extract and control extract.

Toxicity test. The mycelium was homogenized (100 strokes) in a close-fitting Dounce glass-glass homogenizer on ice. The homogenate was centrifuged at $10000 \mathrm{~g}$ for $15 \mathrm{~min}$. The supernatant was used as a toxin extract. Extracts were also prepared from mycelia to which nematodes had been added $150-180 \mathrm{~min}$ before harvest. In this case washed nematodes from one Erlenmeyer flask were added to each $500 \mathrm{ml}$ culture vessel. Before harvest the presence of captured, immobilized nematodes was recorded. Test extract $(100 \mu \mathrm{l})$ and $0.5 \mu \mathrm{l}$ of a nematode suspension (about 20 nematodes) were mixed in a well of a microtitre plate. Moving and non-moving nematodes were counted under a microscope after $1 \mathrm{~h}$ and after $24 \mathrm{~h}$. Distilled water instead of mycelial homogenate was used as a control. The toxicity test was performed on three different $A$. oligospora extracts and two different $D$. candida extracts. Eight wells with nematodes were counted for each extract.

\section{Results}

\section{Effects of $U V$ irradiation on the nematode infection process}

The effects of 0-15 min UV irradiation of $A$. oligospora and $D$. candida are shown in Fig. $1(a, b)$. With no UV irradiation the nematodes stopped moving within the first few hours after attachment and were almost completely filled with hyphae after $24 \mathrm{~h}$. Nematodes added to cultures that had been UV-irradiated for $5 \mathrm{~min}$ were captured but were still alive (moving) the next day. In cultures exposed to UV light for $15 \mathrm{~min}$ the proportion of captured nematodes was also reduced. The effects of 3,5 and $15 \mathrm{~min}$ UV irradiation were followed for $4 \mathrm{~d}$. In all treatments of both fungi the ratio of free to captured nematodes was stable during a $4 \mathrm{~d}$ period (Fig. 2). With the exception of $D$. candida, UV-irradiated for $3 \mathrm{~min}$, a substantial part of the captured nematodes remained motile over the $4 \mathrm{~d}$ period (Fig. 3).

\section{Viability of UV-irradiated mycelia}

Vital staining of the UV-irradiated cultures with methylene blue showed that both fungi were alive even after UV irradiation for $15 \mathrm{~min}$. Dialysis membrane cultures of $A$. oligospora and $D$. candida which had been UV-irradiated for $0,3,5$ and $15 \mathrm{~min}$ were inoculated onto diluted cornmeal agar. $A$. oligospora grew normally after $15 \mathrm{~min}$ UV irradiation, while $D$. candida was more sensitive, showing reduced growth after only $3 \mathrm{~min}$ UV irradiation.

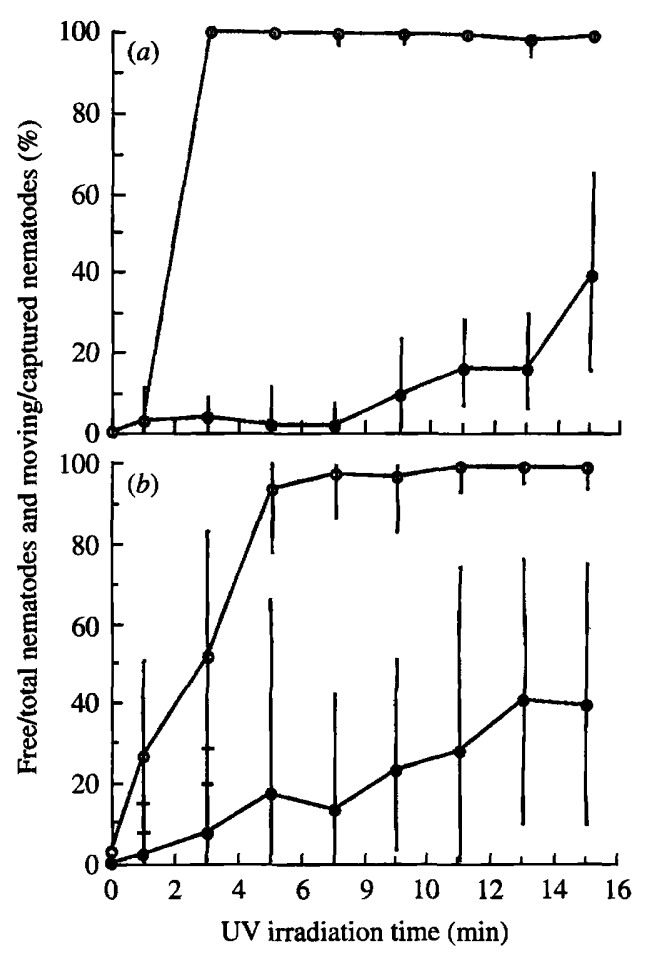

Fig. 1. Effects of UV irradiation on nematode infection by (a) $A$. oligospora and $(b) D$. candida. Free nematodes/total nematodes $(\boldsymbol{O})$ and captured moving nematodes/captured nematodes $(O)$ after 0-15 min UV irradiation are plotted. The data were recorded $24 \mathrm{~h}$ after treatment. Bars indicate SD $(n=10$ for A. oligospora and $12-15$ for $D$. candida).

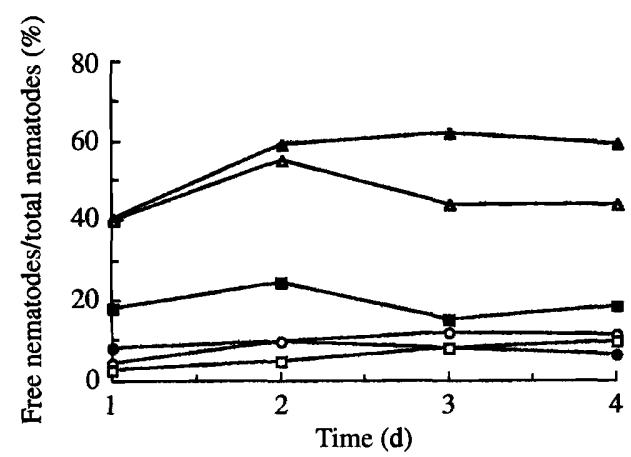

Fig. 2. Effects of UV irradiation on nematode capture during a $4 \mathrm{~d}$ period following treatment. The ratio free nematodes/total nematodes is shown for $A$. oligospora (open symbols) and $D$. candida (filled symbols) UV-irradiated for $3(O, \ominus), 5(\square, \square)$ and $15(\Delta, \Delta) \mathrm{min}$. The results are means of 10 determinations for $A$. oligospora and of 12-15 for D. candida. 


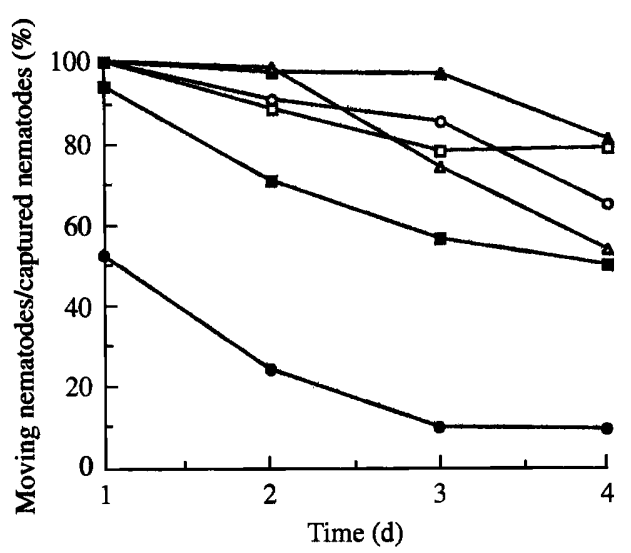

Fig. 3. Effects of UV irradiation on nematode infection during a $4 \mathrm{~d}$ period following treatment. The ratio captured but moving nematodes/total captured nematodes is shown for A. oligospora (open symbols) and $D$. candida (filled symbols) UV-irradiated for $3(O, O)$, $5(\square, \square)$ and $15(\triangle, \Delta)$ min. The results are means of 10 determinations for $A$. oligospora and of $12-15$ for $D$. candida.

However, when D. candida had captured a nematode and further digestion was inhibited because of UV irradiation it was often noticed that many new hyphae were growing around the nematode at the site of contact. After shortterm UV irradiation, nematodes were captured, but no invasive fungal growth and digestion occurred, although the fungi were not killed or unable to grow.

\section{Effects of inhibition of protein synthesis and RNA synthesis on the nematode infection process}

Treatment of the fungi with $25 \mu \mathrm{g}$ cycloheximide $\mathrm{ml}^{-1}$ increased the proportion of captured but moving nematodes relative to the total number of captured nematodes to $82 \%$ in $A$. oligospora without decreasing the growth rate. Only $10 \%$ of the captured nematodes were moving in the $D$. candida samples although cycloheximide did reduce the growth rate (Table 1). Treatment with $100 \mu \mathrm{g}$ cycloheximide $\mathrm{ml}^{-1}$ increased the proportion of captured but moving nematodes to more than $90 \%$ in both fungi but also reduced the growth rate in $A$. oligospora. Following treatment of the fungi with $100 \mu \mathrm{g}$ actinomycin $\mathrm{D} \mathrm{ml}^{-1}, 57 \%$ of nematodes captured by $A$. oligospora and $22 \%$ of nematodes captured by $D$. candida were still moving after $24 \mathrm{~h}$. The growth of both fungi was hampered by this concentration. There were no visible effects of the inhibitors on the nematodes. When inhibitor-treated dialysis membranes were washed with distilled water $1 \mathrm{~h}$ after the nematodes were added the inhibitory effect was negligible.

\section{Effects of UV irradiation on the fungal proteins}

A few minor changes were observed in the polypeptide pattern of both fungi after UV irradiation for 10 and $30 \mathrm{~min}$. Two bands from $A$. oligospora extracts and five

Table 1. Percentages of captured but non-immobilized nematodes following treatment of A. oligospora and D. candida with the protein synthesis inhibitor cycloheximide and the $R N A$ synthesis inhibitor actinomycin $D$

Mean and standard deviation were calculated after arcsin $\sqrt{ }$ moving nematodes/captured nematodes transformation. The ranges in parentheses represent $\pm \mathrm{SD}$ and are presented in this way since they are not symmetrically distributed about the mean after back-transformation. $n$, Number of replicates; nem, total number of captured nematodes counted.

\begin{tabular}{|c|c|c|c|c|c|c|c|c|c|c|}
\hline \multirow[b]{3}{*}{ Treatment } & \multicolumn{10}{|c|}{ Captured moving nematodes/captured nematodes } \\
\hline & \multicolumn{5}{|c|}{ A. oligospora } & \multicolumn{5}{|c|}{ D. candida } \\
\hline & $\%$ & (SD) & $n$ & nem & Growth & $\%$ & (SD) & $n$ & nem & Growth \\
\hline Distilled water & 1 & $(0-4)$ & 5 & 655 & normal & 0 & $(0-2)$ & 4 & 1229 & normal \\
\hline $\begin{array}{l}\text { Cycloheximide } \\
1 \mu \mathrm{g} \mathrm{m}^{-1} \\
1 \mu \mathrm{g} \mathrm{m}^{-1} \text { washed } \\
25 \mu \mathrm{g} \mathrm{ml}^{-1} \\
25 \mu \mathrm{g} \mathrm{ml}^{-1} \text { washed } \\
100 \mu \mathrm{g} \mathrm{ml}^{-1} \\
100 \mu \mathrm{g} \mathrm{ml}^{-1} \text { washed }\end{array}$ & $\begin{array}{r}0 \\
1 \\
82 \\
7 \\
99 \\
9\end{array}$ & $\begin{array}{c}(0-5) \\
(75-88) \\
(97-100) \\
(6-28)\end{array}$ & $\begin{array}{l}3 \\
3 \\
3 \\
1 \\
6 \\
4\end{array}$ & $\begin{array}{r}55 \\
33 \\
121 \\
144 \\
263 \\
208\end{array}$ & $\begin{array}{l}\text { normal } \\
\text { normal } \\
\text { reduced }\end{array}$ & $\begin{array}{r}6 \\
2 \\
10 \\
7 \\
93 \\
1\end{array}$ & $\begin{array}{l}(0-17) \\
(1-5) \\
(6-14) \\
(5-9) \\
(88-90) \\
(0-2)\end{array}$ & $\begin{array}{l}3 \\
3 \\
3 \\
3 \\
6 \\
4\end{array}$ & $\begin{array}{r}571 \\
1339 \\
911 \\
1235 \\
1174 \\
1035\end{array}$ & $\begin{array}{l}\text { normal } \\
\text { reduced } \\
\text { reduced }\end{array}$ \\
\hline $\begin{array}{l}\text { Actinomycin D } \\
20 \mu \mathrm{g} \mathrm{ml}^{-1} \\
20 \mu \mathrm{g} \mathrm{ml}^{-1} \text { washed } \\
100 \mu \mathrm{g} \mathrm{ml}^{-1} \\
100 \mu \mathrm{g} \mathrm{m}^{-1} \text { washed }\end{array}$ & $\begin{array}{c}0.3 \\
4 \\
57 \\
4\end{array}$ & $\begin{array}{c}(0-3) \\
(0-17) \\
(44-69) \\
(0-15)\end{array}$ & $\begin{array}{l}6 \\
5 \\
6 \\
5\end{array}$ & $\begin{array}{l}379 \\
398 \\
611 \\
299\end{array}$ & $\begin{array}{l}\text { reduced } \\
\text { none }\end{array}$ & $\begin{array}{c}4 \\
0 \cdot 2 \\
22 \\
1\end{array}$ & $\begin{array}{l}(1-7) \\
(0-0 \cdot 7) \\
(9-38) \\
(0-5)\end{array}$ & $\begin{array}{l}2 \\
3 \\
3 \\
3\end{array}$ & $\begin{array}{l}437 \\
630 \\
230 \\
221\end{array}$ & $\begin{array}{l}\text { normal } \\
\text { reduced }\end{array}$ \\
\hline
\end{tabular}




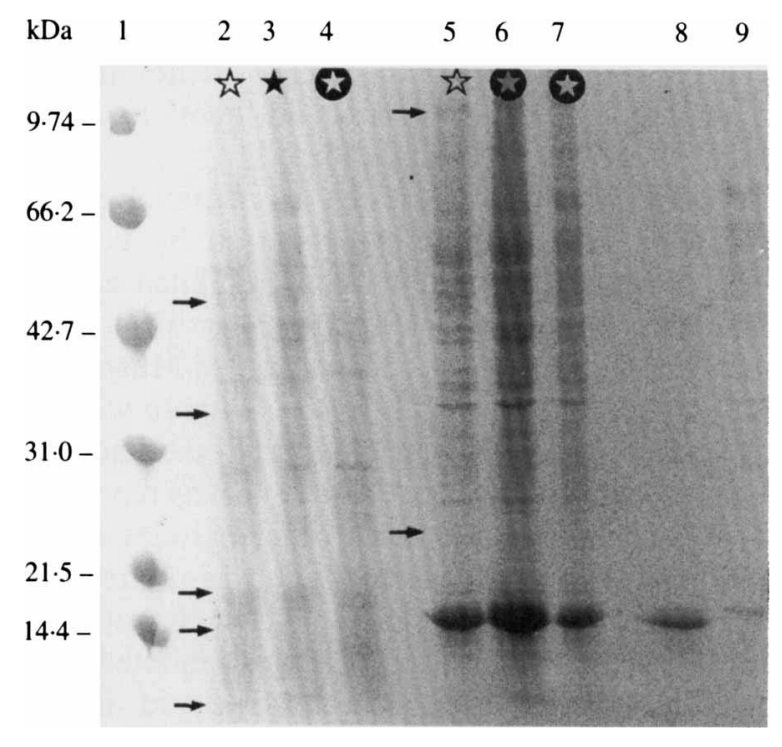

Fig. 4. SDS-PAGE of extracts from $A$. oligospora and $D$. candida mycelia. Lanes: 1 , molecular mass standards; $2-4, D$. candida UVirradiated for 0 (lane 2), 10 (lane 3) and 30 (lane 4) $\mathrm{min}$; 5-7, A. oligospora UV-irradiated for 0 (lane 5), 10 (lane 6) and 30 (lane 7) $\mathrm{min}$; 8-9, mycelial extract of $A$. oligospora treated with PBS (lane 8) or mucin-Sepharose (lane 9). The biological effects of UV irradiation on the mycelia corresponding to the extracts of lanes $2-7$ are indicated by:

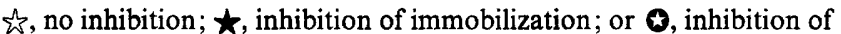
both capture and immobilization. Arrows indicate peptides affected by UV irradiation.

Table 2. Haemagglutination and proteolytic activity of $A$. oligospora and D. candida mycelial extracts exposed to $U V$ irradiation for 0,10 or $30 \mathrm{~min}$

Haemagglutination activity was expressed as number of wells showing haemagglutination of trypsinized and glutaraldehydetreated human blood group A erythrocytes in a twofold dilution series (means of three experiments). Proteolytic activity was measured against Azocoll at pH 5.9. One proteolytic unit (PU) was defined as $\Delta A_{520} \mathrm{ml}^{-1} \mathrm{~h}^{-1}$ (means of five replicates, $\pm \mathrm{SD}$ ).

\begin{tabular}{cccc}
\hline \hline Extract & $\begin{array}{c}\text { UV } \\
\text { irradiation } \\
\text { time (min) }\end{array}$ & $\begin{array}{c}\text { Haemagglutination } \\
\text { activity (wells) }\end{array}$ & $\begin{array}{c}\text { Proteolytic } \\
\text { activity } \\
\text { (PU } \pm \text { SD) }\end{array}$ \\
\hline A. oligospora & 0 & 12 & $0.027 \pm 0.003$ \\
& 10 & 10 & $0.030 \pm 0.004$ \\
& 30 & 11 & $0.027 \pm 0.004$ \\
D. candida & 0 & 0 & $0.035 \pm 0.005$ \\
& 10 & 0 & $0.035 \pm 0.004$ \\
& 30 & 0 & $0.030 \pm 0.003$ \\
\hline \hline
\end{tabular}

bands from $D$. candida extracts disappeared or were less intense (Fig. 4).

\section{A. oligospora lectin}

Mucin treatment of A. oligospora extract resulted in loss of the major peptide band at about $15 \mathrm{kDa}$ (Fig. 4) and a simultaneous total loss of haemagglutinating activity.
Therefore, this major band was concluded to be the $A$. oligospora lectin. This band was not changed by UV irradiation.

The mean haemagglutinating activity expressed as the number of wells showing haemagglutinating activity of three extracts from $A$. oligospora was 12 . Ten minutes of UV irradiation decreased this value to 10 . After $30 \mathrm{~min}$ UV irradiation the corresponding haemagglutinating activity was 11 . D. candida extracts showed no haemagglutinating activity against human blood group A erythrocytes (Table 2).

\section{Proteolytic activity}

No change in proteolytic activity was observed after UV irradiation of mycelial extracts from A. oligospora and $D$. candida for 10 and $30 \mathrm{~min}$ (Table 2).

\section{Toxicity tests}

No toxic effect was observed on the nematode Panagrellus redivivus with the extracts tested. After incubation for $1 \mathrm{~h}$, more than $95 \%$ of the nematodes were moving both in the control and in all fungal extracts. After $24 \mathrm{~h}$ the proportion of moving nematodes in the distilled water control had decreased to $82 \%$ while moving nematodes in all fungal extracts remained between 94 and $96 \%$. The difference between the control and the fungal extract after $24 \mathrm{~h}$ suggests that the nematodes can use nutrients from the extracts but are starved in the distilled water.

\section{Discussion}

A molecule can only be altered by UV irradiation if the light is absorbed. Nucleic acids and proteins ( $\mathrm{S}-\mathrm{S}$ bonds, aromatic amino acids) absorb light in the region 250-260 $\mathrm{nm}$. The effect of UV irradiation on a protein can be denaturation, fragmentation, cross-linkage or formation of aggregates, but the sensitivity is not the same for all proteins (Smith \& Hanawalt, 1969; Whitaker-Dowling \& Youngner, 1988).

The two different effects of UV irradiation in this study, reduced attachment of nematodes to fungal traps and inhibition of the subsequent infection, suggest that there are at least two target sites for the absorbed UV light: one, more sensitive site involved in the sequence of events taking place after attachment but before death of the nematode; and another, less sensitive site destroying molecule(s) involved in the attachment of nematodes. Since attachment of nematodes to the traps is an instantaneous event, all molecules involved in the attachment must be present at the time of contact 
between nematode and trap. The effect of UV irradiation on attachment must therefore be on molecule(s) which are active during the nematode infection process and not on DNA. Treatment of $A$. oligospora and $D$. candida with trypsin or glutaraldehyde in order to destroy surface proteins inhibited attachment of nematodes (NordbringHertz et al., 1982), indicating involvement of proteins in this event.

The results from inhibition studies with cycloheximide suggest that $D$. candida has all the proteins needed for the entire infection process at capture but that in $A$. oligospora induction of new proteins involved in the infection process may take place. If so, the more sensitive UV irradiation effect inhibiting immobilization of nematodes, on D. candida, must also be directly on protein(s). The effect on the infection process after treatment with actinomycin D follows the inhibition of growth, which makes it difficult to connect the effect to steps in the infection process. The change in peptide pattern provides evidence that proteins in both fungi could be affected by UV irradiation under these conditions. The affected proteins may be involved in the infection process. Changes in the peptide pattern after SDS-PAGE reflect changes in molecular mass. This means that fragmentation, cross-linkage and formation of aggregates, but not denaturation of proteins, can be observed.

Nematodes are normally immobilized soon after the penetration of the nematode cuticle, within a few hours after attachment of the nematode to the trap. A toxin has been proposed to be involved in the killing of the nematode (Shepherd, 1955). Immobilization of nematodes has been observed after treatment of nematodes with filtrate of crushed nematodes infected by $A$. oligospora (Olthof \& Estey, 1963). In this study no toxic effects were observed when nematodes were treated with extracts of $A$. oligospora and $D$. candida. The result was the same when the fungi were infecting nematodes prior to the extractions. Similar results have been obtained by J. Grønvold \& M. Tranholm (personal communication), who tested water-soluble and lipid-soluble extracts from 13 nematophagous fungi, including $A$. oligospora. They compared extracts of the fungi with and without infected nematodes and obtained no toxic effects on nematodes with these extracts with the exception of the watersoluble extract of Duddingtonia flagrans with infected nematodes. However, since the fungi normally kept the struggling nematodes for about an hour until the penetration has occurred and are able to keep a moving nematode for several days if the infection process is inhibited as above, it would not be necessary for the fungus to poison the nematode. An alternative explanation offered for the cessation of movement of the nematode is decrease of the high internal turgor pressure of the nematode due to translocation of water and other substances from the nematode to the fungus (Murray \& Wharton, 1990). I suggest that toxins are not involved in the nematode infection process and therefore cannot be the target for the UV irradiation.

A lectin was first suggested to be involved in the attachment of nematodes to the trap by NordbringHertz \& Mattiasson (1979). They inhibited capture of nematodes by treating $A$. oligospora with $N$-acetylgalactosamine. In contrast, Wharton \& Murray (1990) observed $100 \%$ capture when $A$. oligospora was treated with $N$-acetylgalactosamine or with 11 other saccharides. However, they observed the same effect as reported here for UV irradiation, i.e. captured nematodes struggling for at least $2 \mathrm{~d}$, when $A$. oligospora was pretreated with $100 \mathrm{~mm}$-2-deoxyglucose. They concluded that the penetration of the nematode cuticle was inhibited since no infection bulb or hyphae were observed inside the nematode body cavity. The attachment of nematodes has also been reported to be inhibited by 2-deoxyglucose in D. candida (Nordbring-Hertz et al., 1982) and in Monacrosporium rutgerienses and Arthrobotrys conoides (Rosenzweig \& Ackroyd, 1983). However, 2-deoxyglucose is known to be an inhibitor of several biochemical processes such as respiration, glucose metabolism, glucose transport and biosynthesis of cell walls. It thereby inhibits cellular processes such as glucoseinduced activation of spores and cell growth (McKay \& MacLean, 1992; Bourret, 1987; Biely et al., 1971). A lectin has recently been isolated from $A$. oligospora (Rosén et al., 1992). The $A$. oligospora lectin haemagglutinating activity could be inhibited by the glycoproteins mucin and fetuin but not by $\mathrm{N}$-acetylgalactosamine or any other monosaccharide tested. It occurred at the same level in cultures with traps and in trap-free cultures. This lectin is the dominant band after SDS-PAGE of fungal homogenate from $A$. oligospora. The lectin band seems to be unaffected by the UV irradiation and the change in haemagglutinating activity after UV irradiation is negligible. It therefore seems unlikely that the lectin is the target of the UV irradiation effects.

Proteases could be involved in several steps of the nematode infection process, for example activating other enzymes, degrading the nematode cuticle during penetration or degrading the protein content of the nematode. Serine protease inhibitors have been reported to reduce the immobilization rate of nematodes by $A$. oligospora (Tunlid \& Janson, 1991). However, no proteases specific for traps have been detected and no enhancement of proteolytic activities has been observed during the nematode infection process (Persson \& Friman, 1993). Here the proteolytic activity of extracts from both $A$. oligospora and $D$. candida was unaffected by UV irradiation.

In conclusion, the results show that UV irradiation has 
more than one effect on the nematode infection process in the two fungi tested. This makes it possible to separate the attachment from the digestion process. It seems likely that the observed effects involve a direct influence on proteins functioning in the infection of nematodes but do not involve DNA, RNA, or the proposed toxins, lectins and proteases.

I thank Professor B. Nordbring-Hertz for initiating this study and for valuable discussions. I also thank $\mathrm{S}$. Rosén for valuable discussions concerning the $A$. oligospora lectin and $\mathrm{Dr} \mathrm{J}$. Bornman for providing help with the measurement of intensity of the UV irradiation. This study was supported by a grant to B. Nordbring-Hertz from the Swedish Natural Science Research Council.

\section{References}

Bourret, J. A. (1987). The mechanism by which 2-deoxyglucose inhibits glucose-induced activation of Pilobolus longipes spores. Experimental Mycology 11, 307-316.

Biely, P., KrátKy, Z., Kovarík, J. \& Bauer, S. (1971). Effect of 2deoxyglucose on cell wall formation in Saccharomyces cerevisiae and its relation to cell growth inhibition. Journal of Bacteriology 107, 121-129.

Chavira, R., Jr, Burnett, T. J. \& Hageman, J. H. (1984). Assaying proteinases with Azocoll. Analytical Biochemistry 136, 446-450.

DowseTt, J. A. \& REID, J. (1977a). Light microscope observations on the trapping of nematodes by Dactylaria candida. Canadian Journal of Botany 55, 2956-2962.

DowsETT, J. A. \& REID, J. (1977b). Transmission and scanning electron microscope observations on the trapping of nematodes by Dactylaria candida. Canadian Journal of Botany 55, 2963-2970.

Friman, E., Olsson, S. \& Nordbring-HertZ, B. (1985). Heavy trap formation by Arthrobotrys oligospora in liquid culture. FEMS Microbiology Ecology 31, 17-21.

GuRR, E. (1960). Encyclopedia of Microscopic Stains, pp. 213-214. Baltimore: Williams \& Wilkins.

McKAY, D. B. \& MACLEAN, D. J. (1992). Effect of glucose and glucitol analogues on respiration by mycelia of Puccinia graminis. Experimental Mycology 16, 110-118.

MurRay, D. S. \& Wharton, D. A. (1990). Capture and penetration processes of the free-living juveniles of Trichostrongylus colubriformis (Nematoda) by the nematophagous fungus, Arthrobotrys oligospora. Parasitology 101, 93-100.

NORDBRING-HERTZ, B. (1973). Peptide-induced morphogenesis in the nematode-trapping fungus Arthrobotrys oligospora. Physiologia Plantarum 29, 223-233.

Nordbring-HerTZ, B. (1983). Dialysis membrane technique for studying microbial interaction. Applied and Environmental Microbiology 45, 290-293.
Nordbring-Hertz, B. \& Mattiasson, B. (1979). Action of a nematode-trapping fungus shows lectin-mediated host-microorganism interaction. Nature, London 281, 477-479.

Nordbring-Hertz, B., Friman, E. \& Mattiasson, B. (1982). A recognition mechanism in the adhesion of nematodes to nematodetrapping fungi. In Lectins-Biology, Biochemistry, Clinical Biochemistry, vol. II, pp. 83-90. Edited by T. C. Bog-Hansen. Berlin: Walter de Gruyter.

Nordbring-Hertz, B., Jansson, H.-B., Friman, E., Persson, Y., Dackman, C., Hard, T. \& Poloczek, E. (1993). Mechanisms of capture in nematophagous fungi. Film V 2603, IWF, Göttingen, Germany.

Olthof, H. A. \& Estey, R. H. (1963). A nematotoxin produced by the nematophagous fungus Arthrobotrys oligospora Fresenius. Nature, London 197, 514-515.

PERSSON, Y. \& FrImaN, E. (1993). Intracellular proteolytic activity in mycelia of Arthrobotrys oligospora bearing mycoparasitic or nematode-trapping structures. Experimental Mycology 17 (in the Press).

Rosén, S., Ek, B., Rask, L. \& TuNLID, A. (1992). Purification and characterization of a surface lectin from the nematode-trapping fungus Arthrobotrys oligospora. Journal of General Microbiology 138, 2663-2672.

RosenZWEIG, W. D. \& ACKROYD, D. (1983). Binding characteristics of lectins involved in the trapping of nematodes by fungi. Applied and Environmental Microbiology 46, 1093-1096.

SHEPHERD, A. M. (1955). Formation of the infection bulb in Arthrobotrys oligospora Fresenius. Nature, London 175, 475.

Smith, K. C. \& Hanawalt, P. C. (1969). Photochemistry of amino acids and proteins. In Molecular Photobiology. Inactivation and Recovery, pp. 85-95. Edited by K. C. Smith \& P. C. Hanawalt. New York \& London: Academic Press.

SoKAL, R. R. \& RoHLF, F. J. (1981). Biometry. The principles and practice of statistics in biological research, $2 \mathrm{nd}$ edn, pp. 427-428. San Francisco: W. H. Freeman.

TunLID, A. \& JANSON, S. (1991). Proteases and their involvement in the infection and immobilization of nematodes by the nematophagous fungus Arthrobotrys oligospora. Applied and Environmental Microbiology 57, 2868-2872.

VeEnhUis, M., Nordbring-Hertz, B. \& Harder, W. (1985). An electron-microscopical analysis of capture and initial stages of penetration of nematodes by Arthrobotrys oligospora. Antonie van Leeuwenhoek 51, 385-398.

Veenhuis, M., Harder, W. \& Nordbring-HerTz, B. (1989). Occurrence and metabolic significance of microbodies in trophic hyphae of the nematophagous fungus Arthrobotrys oligospora. Antonie van Leeuwenhoek 56, 241-249.

Wharton, D. A. \& MurRay, D. S. (1990). Carbohydrate/lectin interactions between the nematophagous fungus Arthrobotrys oligospora, and the infective juveniles of Trichostrongylus colubriformis (Nematoda). Parasitology 101, 101-106.

WhitakeR-Dowling, P. \& YoungNer, J.S. (1988). Alteration of vesicular stomatitis virus L and NS proteins by uv irradiation implications for the mechanism of host cell shut-off. Virology 164, 171-175.

Wimble, D. B. \& Young, T. W. K. (1984). Ultrastructure of the infection of nematodes by Dactylella lysipaga. Nova Hedwigia $\mathbf{4 0}$, 9-29. 